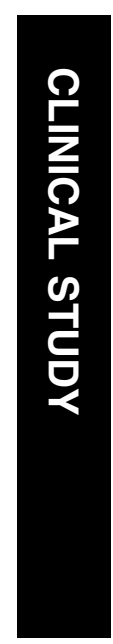

\title{
Anatomical and functional outcome of surgery of primary rhegmatogenous retinal detachment in high myopic eyes
}

${ }^{1}$ Department of Ophthalmology, National Taiwan University Hospital, Taipei, Taiwan

${ }^{2}$ Department of Information Management, Leader University, Tainan, Taiwan

Correspondence: C-H Yang, Department of Ophthalmology, National Taiwan University Hospital, No. 7 Chung-Shan South Road, Taipei 100, Taiwan Tel: +886223123456 ext. 3193 ;

Fax: +886223412875 E-mail: chyang@ha.mc. ntu.edu.tw

Received: 17 March 2006 Accepted: 16 June 2006 Published online:

21 July 2006

\begin{abstract}
Purpose To analyse the anatomical and functional outcome of surgery for primary rhegmatogenous retinal detachment (RRD) in highly myopic eyes.

Methods We retrospectively reviewed the medical records of 111 high myopic patients (111 eyes) with primary RRD treated by scleral buckling or pars plana vitrectomy in a tertiary referral university hospital. The postoperative retinal status and best-corrected visual acuity were recorded. Risk factors including age refractive error, duration of retinal detachment, preoperative visual acuity, extent of detachment, and intraoperative and postoperative complications were evaluated. Multiple logistic regression analysis was used to determine the independent correlation of each variable on anatomical and functional outcome.

Results Primary surgery resulting in retinal reattachment was achieved in 96 (86.5\%) eyes with more than 6 months follow-up (range, 6-60 months). Sixty-eight $(61.3 \%)$ eyes had postoperative corrected visual acuity $20 / 50$ or more. Postoperative complications in high myopic eyes were variable, and the most common was cataract progression (19.8\%). Upon multiple logistic regression analysis, young patients had significantly better anatomical outcome, although the variables including less refraction error, better preoperative visual acuity, scleral buckling procedure, and less surgical intervention showed better functional outcome in our series.

Conclusions The anatomical outcome of surgery for primary RRD in highly myopic
\end{abstract}

S-F Cheng ${ }^{1}$, C-H Yang1', C-H Lee ${ }^{2}$, C-M Yang ${ }^{1}$, J-S Huang ${ }^{1}, \mathrm{~T}-\mathrm{C} \mathrm{Ho}{ }^{1}, \mathrm{C}-\mathrm{P}$ Lin $^{1}$ and M-S Chen ${ }^{1}$

eyes was favourable, and young patients tended to have a higher success rate. Functional outcome was significantly correlated with refractive error, preoperative visual acuity, surgical procedure, and number of vitreoretinal surgery.

Eye (2008) 22, 70-76; doi:10.1038/sj.eye.6702527; published online 21 July 2006

Keywords: rhegmatogenous retinal detachment; high myopia; scleral buckling; pars plana vitrectomy

Introduction

Myopia is the most common ocular abnormality, and it is generally classified as high myopia when refractive error exceeds -6 diopters (D). ${ }^{1}$ The prevalence of high myopia has been reported to range from 0.2 to $9.6 \%$ in the previous literature, especially greatest in Asians. ${ }^{2-4}$ Visual disabilities owing to high myopia include glaucoma, peripheral breaks, posterior pole degeneration, and posterior vitreous detachment. Rhegmatogenous retinal detachment (RRD) is also a serious complication that may threaten central vision. ${ }^{5}$

Although the anatomical success rate of vitreoretinal surgery has improved over the last decade, vitreoretinal surgery of high myopic eyes remains a great challenge for surgeons. From the surgical point of view, retinal detachment in highly myopic eyes differs from emmetropic or low-grade myopic eyes. Because of very long axial length with generalized thinning of the sclera, the potential for muscle avulsion, vortex vein damage, haemorrhage, retained subretinal fluid upon internal drainage, 
and globe perforation during surgery upon exposure and placing the anchor suture were noted in highly myopic eyes. ${ }^{6-8}$ Comparing with the general population, the anatomical outcome of this group was thought to be poor. Many factors have been found to influence recovery of vision following surgery in the general population, including patient age, refractive error (no or mild myopia), duration of retinal detachment, preoperative visual acuity, lens status, extent of detachment, and intraoperative and postoperative complications. ${ }^{9-12}$ However, even though these variables have been studied extensively, the relationship between the various factors and surgical outcome of RRD in highly myopic patients have not been well established in a larger series.

In this present study, we assessed the long-term anatomic and functional visual outcome of 111 consecutive patients who underwent retinal surgery for primary RRD. In addition to research of anatomical and functional outcome, we also paid attention to various possible factors correlated with treatment efficacy and visual recovery in highly myopic eyes.

\section{Patients and methods}

For this retrospective study, we reviewed the medical charts of 140 consecutive, highly myopic patients with primary RRD between April 2000 and October 2003 in a tertiary referral university hospital. Thirty patients were excluded because of incomplete medical records and previous ocular or trauma history. The enrolled patients included 56 male and 55 female patients, with a mean age of 33.2 years (range, 16-57 years). The degree of myopia was more than or equal to $-6 \mathrm{D}$ (range, -6 to $-24 \mathrm{D}$, mean of $-9.7 \pm 4.0 \mathrm{D})$. All eyes were phakic without dense cataract, and were absent of any history of intraocular surgery or recent eye trauma. The mean follow-up was 19.7 months (range, 6-60 months). Exclusion criteria included primary retinal detachment caused by macular hole, pre-existing macular lesion, diabetic retinopathy, or underlying systemic diseases that could interfere with visual outcome. A detailed preoperative and postoperative retinal drawing was collected.

The preoperative data recorded included age, sex, refractive error, best-corrected visual acuity (BCVA), lens status, extent of retinal detachment, interval of retinal detachment, and break type. Visual acuity was measured by Snellen visual acuity chart and converted into logarithm of the minimum angle of resolution (logMAR) equivalents for statistical comparison. The intraoperative data recorded included the type and size of episcleral exoplants, the material of intravitreal temponade, any external drainage of subretinal fluid, method of chorioretinal adhesion, and complications. The postoperative data included initial and final anatomic success rate, BCVA, and complications.

In the scleral buckling group, all the chorioretinal adhesions were created with cryopexy around the breaks. An exoplant (silicon sponge or band) was used to support the peripheral retinal breaks. Most eyes received neither external drainage of the subretinal fluid nor pneumatic retinopexy.

In the pars plana vitrectomy group, all 19 eyes underwent $360^{\circ}$ encircling buckle (Gore-Tex ${ }^{\circledR}$, polytetrafluoroethylene, ${ }^{13,14}$ WL Gore \& Associates Inc., Flagstaff, AZ, USA) and standard three-port pars plana vitrectomy. Subretinal fluid was drained followed by a fluid-gas exchange. After complete attachment of the retina, the surgeons applied endophotocoagulation around the breaks for chorioretinal adhesion. Gas (C3F8 or SF6) or silicon oil temponade was used to support the retina in these cases. These patients were instructed to maintain the prone position following the surgery.

Statistical analyses were performed using the Statistical Program for Social Sciences software (SPSS 13.0, SPSS Inc., Chicago, IL, USA). In the first step, $\chi^{2}$ test, Fisher's exact test, and Student's $t$-test were used to analyse each variant individually for univariate analysis. In the second step, multiple logistic regression models were used for elucidating the independent influence of each potential factor on anatomical and functional outcome. However, problems of multicollinearity in regression would arise if we had performed the logistic regression to analyse our investigative data. Therefore, it was necessary to build models by using the methods of model selection. In the procedure of building models, we utilized the forward selection, backward elimination, and stepwise selection to select the goodness-of-fit and meaning models for our data set. A $P$-value of 0.05 or less was considered to be statistically significant.

\section{Results}

All 111 patients received surgery for RRD. The patients' ages ranged from 16 to 57 years $(33.2 \pm 10.6$ years, mean $\pm S D$ ). Fifty-six of the patients were male and 55 were female. Refractive error was -6 to $-24 \mathrm{D}$ $(-9.7 \pm 4.0 \mathrm{D})$. Sixty-one of 111 eyes $(55.0 \%)$ had a retinal break located within lattice degeneration; 26 eyes (23.4\%) had flap tears; 19 eyes (17.1\%) had a single atrophic hole. The macula was attached in 56 of the 111 eyes (50.5\%) and was detached in 55 eyes (49.5\%). Patients underwent follow-up for 6-60 months with a mean of 19.3 months.

In the primary surgery, 92 eyes underwent scleral buckling, whereas 19 eyes underwent pars plana vitrectomy. The choice of surgical procedure was based upon clinical evaluation and surgeons' preference. In all 
111 eyes, the retina was reattached in 96 eyes with a single procedure $(86.5 \%)$, and all eyes were reattached with more than two procedures. The anatomical success rate in the scleral buckling group was 78 eyes $(84.8 \%)$, whereas in the pars plana vitrectomy group, successful outcome was achieved in 18 eyes (94.7\%) with one operation.

Table 1 illustrates the possible factors for anatomical outcome by univariate analysis. The difference between successful and failed primary retinal surgery was statistically significant upon evaluation of age and refractive error calculated by Student's $t$-test. After multivariate analysis, only the age of the patient showed a significant correlation (odds ratio (OR): 1.13, 95\% confidence interval (CI): 1.06-1.21) with anatomical outcome independently. Factors that showed no significant association included sex, duration of retinal detachment, preoperative BCVA, macular involvement, break type, extent of detachment, and surgical procedure.
The mean best-corrected Snellen visual acuity was 20/182 before vitreoretinal surgery and 20/63 at final exam. Final BCVA of $20 / 50$ or better was seen in 68 of 111 eyes $(61.3 \%)$. Table 2 illustrates the possible factors significant for visual outcome by univariate analysis. We found that preoperative BCVA, macular involvement, extent of detachment, surgical procedure, and the number of vitreoretinal procedures showed statistically significant differences in the final visual outcome. By multiple logistic regression analysis, the final visual acuity was influenced by refractive error, preoperative BCVA, surgical procedure, and number of vitreoretinal procedures (Table 3).

No intraoperative complications were observed in any of our patients. Postoperative complications included cataract formation (22 eyes, 19.8\%), intraocular pressure elevation (six eyes, $5.4 \%$ ), failed primary surgery (nine eyes, $8.1 \%$ ), recurrent detachment (six eyes, $5.4 \%$ ), macular change (six eyes, $5.4 \%$ ), buckle extrusion

Table 1 Anatomic outcome of retinal surgery in high myopia patients

\begin{tabular}{|c|c|c|c|c|}
\hline Variable & Patients $(\mathrm{n}=111)$ & $\begin{array}{c}\text { Success after primary } \\
\text { surgery }(\mathrm{n}=96)\end{array}$ & $\begin{array}{c}\text { Failure after primary } \\
\text { surgery }(\mathrm{n}=15)\end{array}$ & P-value \\
\hline \multicolumn{5}{|l|}{ Sex } \\
\hline Male & 56 & 48 & 8 & \multirow[t]{2}{*}{$0.810^{\mathrm{a}}$} \\
\hline Female & 55 & 48 & 7 & \\
\hline Age $($ mean $\pm S D)$ & $33.2 \pm 10.6$ & $31.5 \pm 9.9$ & $43.5 \pm 9.3$ & $<0.0001^{\mathrm{b}, *}$ \\
\hline Refractive error (mean $\pm S D$ ) & $-9.7 \pm 4.0$ & $-9.3 \pm 3.7$ & $-11.8 \pm 5.1$ & $0.025^{\mathrm{b}, *}$ \\
\hline \multicolumn{5}{|l|}{ Duration of retinal detachment } \\
\hline$\leqslant 7$ days & 67 & 56 & 11 & \multirow[t]{2}{*}{$0.269^{\mathrm{a}}$} \\
\hline$>7$ days & 44 & 40 & 4 & \\
\hline \multicolumn{5}{|l|}{ Preoperative VA } \\
\hline$<20 / 50$ & 67 & 56 & 11 & \multirow[t]{2}{*}{$0.269^{\mathrm{a}}$} \\
\hline$\geqslant 20 / 50$ & 44 & 40 & 4 & \\
\hline \multicolumn{5}{|l|}{ Macula involvement } \\
\hline On & 56 & 47 & 9 & \multirow[t]{2}{*}{$0.426^{\mathrm{a}}$} \\
\hline Off & 55 & 49 & 6 & \\
\hline \multicolumn{5}{|l|}{ Type of break } \\
\hline Lattice degeneration & 61 & 54 & 7 & \multirow[t]{5}{*}{$0.411^{\mathrm{a}}$} \\
\hline Flap tear & 26 & 20 & 6 & \\
\hline Atrophic hole only & 19 & 18 & 1 & \\
\hline Invisible & 4 & 3 & 1 & \\
\hline Giant tear & 1 & 1 & 0 & \\
\hline \multicolumn{5}{|l|}{ Quadrant of retinal detachment } \\
\hline 1 & 58 & 48 & 10 & \multirow[t]{2}{*}{$0.229^{\mathrm{a}}$} \\
\hline$>2$ & 53 & 48 & 5 & \\
\hline \multicolumn{5}{|l|}{ Type of surgery } \\
\hline SB & 92 & 78 & 14 & \multirow[t]{2}{*}{$0.248^{\mathrm{a}}$} \\
\hline PPV & 19 & 18 & 1 & \\
\hline
\end{tabular}

PPV, pars plana vitrectomy; SB, scleral buckling; SD, standard deviation; VA, visual acuity.

${ }^{\mathrm{a}} \chi^{2}$ test.

'Student's $t$-test.

${ }^{*} P<0.05$ 
Table 2 Functional outcome of retinal surgery in high myopia

\begin{tabular}{|c|c|c|c|c|}
\hline Variable & $\begin{array}{l}\text { Patients } \\
(\mathrm{n}=111)\end{array}$ & $\begin{array}{l}\text { Postoperative Snellen } \\
V A \geqslant 20 / 50(\mathrm{n}=68)\end{array}$ & $\begin{array}{l}\text { Postoperative Snellen } \\
V A<20 / 50(\mathrm{n}=43)\end{array}$ & P-value \\
\hline \multicolumn{5}{|l|}{ Sex } \\
\hline Male & 56 & 36 & 20 & \multirow[t]{2}{*}{$0.509^{\mathrm{a}}$} \\
\hline Female & 55 & 32 & 23 & \\
\hline Age $($ mean $\pm S D)$ & $33.2 \pm 10.6$ & $31.6 \pm 9.9$ & $35.6 \pm 11.3$ & $0.054^{\mathrm{b}}$ \\
\hline Refractive error (mean $\pm S D$ ) & $-9.7 \pm 4.0$ & $-8.5 \pm 2.6$ & $-11.5 \pm 5.0$ & $<0.0001^{\mathrm{b}, *}$ \\
\hline \multicolumn{5}{|l|}{ Duration of macular detachment } \\
\hline$\leqslant 7$ days & 67 & 42 & 27 & \multirow[t]{2}{*}{$0.7677^{\mathrm{a}}$} \\
\hline$>7$ days & 44 & 28 & 16 & \\
\hline \multicolumn{5}{|l|}{ Preoperative VA } \\
\hline$<20 / 50$ & 67 & 28 & 39 & \multirow{2}{*}{$<0.0001^{a, *}$} \\
\hline$\geqslant 20 / 50$ & 44 & 40 & 4 & \\
\hline \multicolumn{5}{|l|}{ Macula involvement } \\
\hline On & 56 & 42 & 14 & \multirow{2}{*}{$0.003^{\mathrm{a}, *}$} \\
\hline Off & 55 & 26 & 29 & \\
\hline \multicolumn{5}{|l|}{ Type of break } \\
\hline Lattice degeneration & 61 & 34 & 27 & \multirow[t]{5}{*}{$0.110^{\mathrm{a}}$} \\
\hline Flap tear & 26 & 15 & 11 & \\
\hline Atrophic hole only & 19 & 15 & 4 & \\
\hline Invisible & 4 & 4 & 0 & \\
\hline Giant tear & 1 & 0 & 1 & \\
\hline \multicolumn{5}{|l|}{ Quadrant of retinal detachment } \\
\hline 1 & 58 & 43 & 15 & \multirow[t]{2}{*}{$0.004^{\mathrm{a}, *}$} \\
\hline$>2$ & 53 & 25 & 28 & \\
\hline \multicolumn{5}{|l|}{ Type of surgery } \\
\hline SB & 92 & 63 & 29 & \multirow[t]{2}{*}{$0.001^{\mathrm{a}, *}$} \\
\hline PPV & 19 & 5 & 14 & \\
\hline \multicolumn{5}{|l|}{ Number of operation } \\
\hline 1 & 96 & 64 & 32 & \multirow[t]{2}{*}{$0.001^{\mathrm{a}, *}$} \\
\hline$>2$ & 15 & 4 & 11 & \\
\hline
\end{tabular}

PPV, pars plana vitrectomy; SB, scleral buckling; SD, standard deviation; VA, visual acuity.

${ }^{\mathrm{a}} \chi^{2}$ test.

'Student's $t$-test.

${ }^{*} P<0.05$

Table 3 Functional outcome of retinal surgery (final BCVA more than 20/50) in high myopia by multiple logistic regression analysis

\begin{tabular}{lrrr}
\hline Variable & OR & $95 \%$ CI & P-values \\
\hline Refraction error & 1.1856 & $1.0056-1.3874$ & 0.0413 \\
Preoperative BCVA & 10.8457 & $3.1688-38.0250$ & 0.0028 \\
Surgical technique & 0.1543 & $0.0505-0.7934$ & 0.0219 \\
Number of operation & 0.0823 & $0.0265-0.5872$ & 0.0070 \\
\hline
\end{tabular}

BCVA, best-corrected visual acuity; CI, confidence interval; OR, odds ratio.

*Statistically significant.

(four eyes, 3.6\%), and strabismus (two eyes, 1.8\%). The most common complication was cataract formation, which predominantly presented as posterior subcapsular opacity. The incidence of cataract was $50 \%$ in both the scleral buckling and pars plana vitrectomy groups.

\section{Discussion}

High myopia is a major cause of legal blindness in many developed countries. ${ }^{15}$ It affects approximately $2 \%$ of the general population and constitutes $27-33 \%$ of myopic 
eyes. ${ }^{1}$ The prevalence of high myopia in schoolchildren under the age of 18 years in Taiwan was $24 \%$ in girls and $18 \%$ in boys..$^{15}$ The prevalence was higher than Western countries. In previous reports, myopia was known to be the most striking risk factor for RRD, and the risk of RRD increases with an increase in refractive error. ${ }^{16}$

Lattice degeneration may predispose patients to retinal detachment, and is found in $20-30 \%$ of all eyes with RRD. ${ }^{17}$ In published reports, lattice degeneration contributes to the tendency of RRD to develop in myopic eyes. ${ }^{18-20}$ In our series, lattice degeneration was associated with $55 \%$ of eyes with retinal detachment. In a study of 436 eyes with high myopia, Celorio and Pruett ${ }^{18}$ found $33.0 \%$ eyes had lattice degeneration of the retina. Rodriguez et $a^{21}$ demonstrated that lattice degeneration was present in 50\% of highly myopic retinae, and $71 \%$ had tears associated with the lattice degeneration. People with high myopia need to undergo follow-up of the retina more intensively for early detection of lattice degeneration and breaks. Prophylactic retinal photocoagulation should also be considered in high-risk patients.

The anatomical success rate was $86.5 \%$ after primary vitreoretinal surgery in our present study. Rodriguez et $a l^{21}$ reported a $92.5 \%$ (37 of the 40 eyes) reattachment rate in patients with myopia more than $5 \mathrm{D}$, who underwent primary scleral buckling. Kwok et $a l^{22}$ reported a primary anatomical success rate of $86.1 \%$ in patients who underwent scleral buckling and $75.0 \%$ in those following pars plana vitrectomy. In yet another study, El-Rayes reported success rates of 85.71 and $94.62 \%$ in treating retinal detachment in high myopes with scleral buckling and pars plana vitrectomy, respectively (American Academy Ophthalmology Subspecialty Day, Retina, 2003, Anaheim, LA, USA). Comparing the postoperative results ranging from 64.5 to $88.0 \%$ in other reports, ${ }^{23-26}$ in patients with all kinds of refractive error, the anatomical success rate was quite favourable in highly myopic eyes despite the high risk and difficulty in vitreoretinal surgery.

RRD related to high myopia in young patients tended to have a higher primary success rate in our study. Younger people are known to have less vitreal syneresis, better pumping effect, and stronger reparative ability of the retina pigment epithelium than the elderly. This may be the cause of more anatomical success after primary scleral buckling. The amount of refractive error is not a significant factor associated with the anatomical outcome of RRD in high myopes. Although pars plana vitrectomy offered better anatomical results $84.8 \%$ in scleral buckling vs $94.7 \%$ in pars plana vitrectomy), which is comparable to other studies, the surgical procedure had no significant correlation with anatomical outcome.
Generally, postoperative visual outcome is less satisfactory than the anatomical result, mainly because of the permanent functional damage to the photoreceptors within the macula. Our study showed that $61.3 \%$ eyes obtained a postoperative vision of 20/50 or better, which is comparable with the previous studies. Rodriguez et $a^{21}$ reported that $65 \%$ of highly myopic eyes attained a final visual acuity of $20 / 40$ or better after 6 months follow-up. Kwok et $a^{22}$ demonstrated that $63.1 \%$ of patients from the scleral buckling group and $62.5 \%$ patients from the pars plana vitrectomy group achieved postoperative visual acuity of $20 / 60$ or better. El-Rayes reported that 77.91 and $94.32 \%$ of patients with high myopia had postoperative improvement of vision by more than 2 Snellen lines in the scleral buckling and pars plana vitrectomy groups, respectively (AAO Subspecialty Day, Retina, 2003, Anaheim, LA, USA).

According to the multiple logistic regression analysis in our study, four variables correlated with the functional outcome. First, refractive error reached statistical significance (OR: 1.18; 95\% CI: 1.01-1.39) in visual outcome. Patients with greater myopic refractive error had worse final vision. The influence of refraction in visual recovery studied before was variable. Most of the previous studies reported that refractive error plays no role in visual recovery. ${ }^{12,27-29}$ However, our results differed from these studies, but supported the result of Yang et al. ${ }^{29}$ Their study reported that patients with lowgrade myopia $(<-6 \mathrm{D})$ had better visual outcome than the high-myopia group. The pre-existing macular dysfunction and lessened potential of photoreceptor cells to recover after surgery may account for this result. Second, preoperative visual acuity was the factor most highly correlated with functional outcome (OR: 10.98; 95\% CI: 3.17-38.03). This result supports the findings of other previous studies that the better the preoperative visual acuity, the better the postoperative visual recovery. $5,10,27$ Third, the use of scleral buckling was associated with better final visual acuity (OR: 0.20 ; $95 \%$ CI: 0.05-0.79). The rate of postoperative visual acuity of $20 / 50$ or more in pars plana vitrectomy group (26.3\%) was less than the scleral buckling group (68.5\%). This was most likely because vitrectomy was used only in more complicated cases, and when the preoperative condition was judged to be unfavourable. In our series of high myopes, most RRD was treated initially with scleral buckling, and $61.3 \%$ of patients attained the final vision of 20/50 or even better. Fourth, the number of vitreoretinal procedures was also correlated with visual outcome (OR: 0.79; 95\% CI: 0.03-0.59). The patients who underwent only one vitreoretinal surgery had better visual recovery than those who required more than two surgeries. 
Postoperative complications of primary vitreoretinal surgery in highly myopic eyes included cataract progression, intraocular pressure elevation, unsuccessful surgery, recurrent detachment, macular change, buckle extrusion, and strabismus. In our series, $19.8 \%$ of eyes had cataract progression requiring extraction of the lens in $36.4 \%$. Kwok et $a l^{22}$ studied 52 eyes with RRD in high myopes. The percentage of postoperative cataract progression requiring extraction was $7.7 \%$ after pars plana vitrectomy and $2.9 \%$ after scleral buckling. Most postoperative cataract progression in our series presented as posterior subcapsular opacity, and it differed from previous studies. A study by de Bustros et $a l^{30}$ demonstrated that the development and progression of cataract is a common complication after pars plana vitrectomy, especially in those with nuclear sclerosis. To our knowledge, the mechanisms for the association between myopia and cataract are still not known. Micelli-Ferrari et $a l^{31}$ suggested that retinal lipid peroxidation might play a key role in human cataractogenesis, especially in the myopic type. Lim et $a l^{32}$ illustrated that increasing axial length may tend to deprive the posterior lens of nutrition. Further work is needed to examine possible mechanisms for the relationship.

The chief weakness of the present study is the retrospective, non-controlled nature of the data collection. The duration of detachment was determined mainly from the description of patients and medical records. This might explain the negative correlation of duration of detachment with visual outcome, which was thought to be significantly correlated. The strengths of this study include the large number of cases with long follow-up interval and accurate medical records offering detailed, intact, and valuable information for further analysis.

In summary, the anatomical outcome was favourable compared to patients without high refractive error. Young patients tended to have a higher primary success rate. The recovery of vision 20/50 or better occurred in approximately $61.3 \%$ of patients. Good preoperative visual acuity, less refractive error, performance of scleral buckling, and reduced time associated with vitreoretinal surgery are the significant predictors of better functional outcome. The results of this study provide valuable information to physicians on the clinical management of RRD in highly myopic eyes as well as in the evaluation of potential visual recovery.

\section{References}

1 Curtin BJ. The Myopias: Basic Science and Clinical Management. Harper \& Row: Philadelphia, PA, 1985.
2 Sperduto RD, Seigel D, Roberts J, Rowland M. Prevalence of myopia in the United States. Arch Ophthalmol 1983; 101: 405-407.

3 Michaels DD. Visual Optics and Refraction: A Clinical Approach, 2nd ed., Mosby: St Louis, MO, 1980.

4 Gilmartin B. Myopia: precedents for research in the twenty-first century. Clin Exp Ophthalmol 2004; 32: 305-324.

5 Burton TC. Preoperative factors influencing anatomic success rates following retinal detachment surgery. Trans Sect Ophthalmol Am Acad Ophthalmol Otolaryngol 1977; 83: 499-505.

6 Schepens CL. Retinal Detachment and Allied Disease, Vol II, WB Saunders: Philadelphia, PA, 1983.

7 Glazer LC, Mieler WF, Devenyi RG, Burton TC. Complications of primary scleral buckling procedures in high myopia. Retina 1990; 10: 170-172.

8 Mansour AM, Traboulsi EI, Jalkh AE. Failure of subretinal fluid drainage during scleral buckling procedure in high myopia. Ann Ophthalmol 1985; 17: 636-637.

9 Ross WH, Stockl FA. Visual recovery after retinal detachment. Curr Opin Ophthalmol 2000; 11: 191-194.

10 Sharma T, Challa JK, Ravishankar KV, Murugesan R. Scleral buckling for retinal detachment. Predictors for anatomic failure. Retina 1994; 14: 338-343.

11 Grizzard WS, Hilton GF, Hammer ME, Taren D. A multivariate analysis of anatomic success of retinal detachments treated with scleral buckling. Graefes Arch Clin Exp Ophthalmol 1994; 232: 1-7.

12 Burton TC, Lambert Jr RW. A predictive model for visual recovery following retinal detachment surgery. Ophthalmology 1978; 85: 619-625.

13 Tawakol ME, Peyman GA, Liu KR, Kaufman HE. Gore-Tex soft tissue bands as scleral explants in rabbits: a preliminary histologic study. Ophthalmic Surg 1989; 20: 199-201.

14 Korobelnik JF, D'Hermies F, Chauvaud D, Legeais JM, Hoang-Xuan T, Renard G. Expanded polytetrafluoroethylene episcleral implants used as encircling scleral buckling an experimental and histopathological study. Ophthalmic Res 2000; 32: 110-117.

15 Lin LK, Shih YF, Hsiao CK, Chen CJ, Lee LA, Hung PT. Epidemiologic study of the prevalence and severity of myopia among schoolchildren in Taiwan in 2000. J Formos Med Assoc 2001; 100: 684-691.

16 The Eye Disease Case-Control Study Group. Risk factors for idiopathic rhegmatogenous retinal detachment. Am J Epidemiol 1993; 137: 749-757.

17 Thomas JL. Retina and vitreous. In: Basic and Clinical Science Course. American Academy of Ophthalmology, 2004-2005, pp 258-259.

18 Celorio JM, Pruett RC. Prevalence of lattice degeneration and its relation to axial length in severe myopia. Am J Ophthalmol 1991; 111: 20-23.

19 Burton TC. The influence of refractive error and lattice degeneration on the incidence of retinal detachment. Trans Am Ophthalmol Soc 1989; 87: 143-155.

20 Murakami-Nagasako F, Ohba N. Phakic retinal detachment associated with atrophic hole of lattice degeneration of the retina. Graefes Arch Clin Exp Ophthalmol 1983; 220: 175-178.

21 Rodriguez FJ, Lewis H, Kreiger AE, Yoshizumi ZO, Sidikaro Y. Scleral buckling for rhegmatogenous retinal detachment associated with severe myopia. Am J Ophthamol 1991; 111: 595-600.

22 Kwok AK, Cheng LL, Tse MW, Cheung EY, Lam DS. Outcomes of primary rhegmatogenous retinal detachment 
in myopes of five or more diopters. Ophthalmic Surg Lasers 2002; 33: 188-194.

23 Sullivan PM, Luff AJ, Aylward GW. Results of primary retinal reattachment surgery: a prospective audit. Eye 1997; 11: 869-871.

24 Hakin KN, Lavin MJ, Leaver PK. Primary vitrectomy for rhegmatogenous retinal detachment. Graefes Arch Clin Exp Ophthalmol 1993; 231: 344-346.

25 Tornambe PE, Hilton GF. Pneumatic retinopathy: a multicenter randomized controlled clinical trial comparing pneumatic retinopexy with scleral buckling. Ophthalmology 1989; 96: 772-783.

26 Tani P, Robertson DM, Langworthy A. Prognosis for central vision and anatomic reattachment in rhegmatogenous retinal detachment with macula detached. Am J Ophthalmol 1981; 92: 611-620.

27 Oshima Y, Yamanishi S, Sawa M, Motokura M, Harino S, Emi K. Two-year follow-up study comparing primary vitrectomy with scleral buckling for macula-off rhegmatogenous retinal detachment. Jpn J Ophthalmol 2000; 44: $538-549$.
28 Kaufman PL. Prognosis of primary rhegmatogenous retinal detachment. 2. Accounting for and predicting final visual acuity in surgical reattached cases. Acta Ophthalmol 1976; 54: 61-74.

29 Yang CH, Lin HY, Huang JS, Ho TC, Lin CP, Chen MS et al. Visual outcome in primary macula-off rhegmatogenous retinal detachment treated with scleral buckling. J Formos Med Assoc 2004; 103: 212-217.

30 de Bustros S, Thompson JT, Michels RG, Enger C, Rice TA, Glaser BM. Nuclear sclerosis after vitrectomy for idiopathic epiretinal membranes. Am J Ophthalmol 1988; 105: 160-164.

31 Micelli-Ferrari T, Vendemiale G, Grattagliano I, Boscia F, Arnese L, Altomare E et al. Role of lipid peroxidation in the pathogenesis of myopic and senile cataract. Br J Ophthalmol 1996; 80: 840-843.

32 Lim R, Mitchell P, Cumming RG. Refractive associations with cataract: the Blue Mountains Eye Study. Invest Ophthalmol Vis Sci 1999; 40: 3021-3026. 